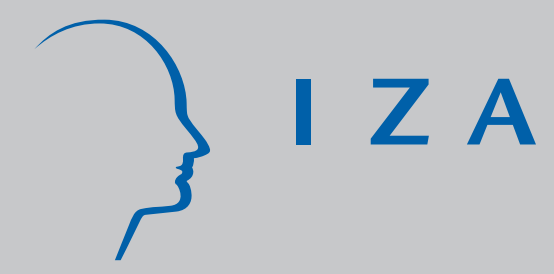

IZA DP No. 1120

Race, Performance, Pay and Retention among National Basketball Association Head Coaches

Lawrence M. Kahn

April 2004 


\title{
Race, Performance, Pay and Retention among National Basketball Association Head Coaches
}

\author{
Lawrence M. Kahn \\ Cornell University, CESifo \\ and IZA Bonn
}

\section{Discussion Paper No. 1120 \\ April 2004}

\author{
IZA \\ P.O. Box 7240 \\ 53072 Bonn \\ Germany \\ Phone: +49-228-3894-0 \\ Fax: +49-228-3894-180 \\ Email: iza@iza.org
}

Any opinions expressed here are those of the author(s) and not those of the institute. Research disseminated by IZA may include views on policy, but the institute itself takes no institutional policy positions.

The Institute for the Study of Labor (IZA) in Bonn is a local and virtual international research center and a place of communication between science, politics and business. IZA is an independent nonprofit company supported by Deutsche Post World Net. The center is associated with the University of Bonn and offers a stimulating research environment through its research networks, research support, and visitors and doctoral programs. IZA engages in (i) original and internationally competitive research in all fields of labor economics, (ii) development of policy concepts, and (iii) dissemination of research results and concepts to the interested public.

IZA Discussion Papers often represent preliminary work and are circulated to encourage discussion. Citation of such a paper should account for its provisional character. A revised version may be available on the IZA website (www.iza.org) or directly from the author. 
IZA Discussion Paper No. 1120

April 2004

\section{ABSTRACT}

\section{Race, Performance, Pay and Retention among National Basketball Association Head Coaches*}

This paper estimates racial differences in the retention probability, pay and performance of NBA coaches over the 1996-2003 period. Using a hazard function approach, I find small and statistically insignificant racial differences in the exit hazard, conditional on team performance, team payroll, and a variety of coaching quality indicators. There were also statistically insignificant racial differences in the quit and discharge hazards, all else equal. Further, among marginal coaches, I find no racial performance differentials, all else equal. Finally, controlling for performance and qualifications, I find small and statistically insignificant racial differences in annual compensation, total contractwide compensation, and contract duration. Together, these findings do not suggest that black NBA coaches are subject to racial discrimination in entry, pay or retention.

JEL Classification: J71, J44, J15, J63

Keywords: discrimination, professional sports, managers

Lawrence M. Kahn

264 Ives Hall

Cornell University

Ithaca, NY 14853

USA

Tel.: +1 6072550510

Fax: +1 6072554496

Email: Imk12@cornell.edu

\footnotetext{
* Preliminary draft. Comments welcome. Please do not quote without author's permission. The author is greatly indebted to Richard Walker of the Gaston Gazette for obtaining salary data.
} 


\section{Introduction}

The National Basketball Association (NBA) is seen by many as an oasis of economic opportunity for highly skilled African-American athletes. Roughly $80 \%$ of the league's players are black. Of the 42 players who as of the 2001-2 season had signed contracts with annual salaries of more than $\$ 10$ million (the top decile of the league's 415 players), fully 37 (88\%) were black. ${ }^{1}$ The last time a white player won the league's Most Valuable Award was 1986 (Larry Bird). Of the 50 players who had ever been on an NBA allstar team before signing their current contracts (as of the 2001-2 season), only four were white.

Black success in the NBA has progressed to the coaching ranks, where for the 2002-3 season, 13 of the NBA's 29 coaches were black, representing a much higher percentage than in football or baseball. For example, in Major League Baseball in 2003, only 7 of 30 managers were black or Hispanic, and in the NFL, only 3 of 32 coaches in 2003 were black (Kahn and Shah 2003). Some journalistic accounts of race and the NBA suggest a recently-developed color-blindness in the treatment of black and white coaches. For example, Rhoden (2004) argues that some recent turnover among black and white NBA coaches represented "equal opportunity hiring and firing” by general managers (GMs). Specifically, in one instance, a black GM replaced a white coach with another white coach, while on another team, the black GM fired a black coach and replaced him with a black coach. Not only were the coaching changes racially neutral, but Rhoden (2004) found it noteworthy that minorities had broken into the executive ranks as well. ${ }^{2}$ Yet despite this evidence suggesting that black coaches have good opportunities in the NBA, there is an undercurrent of suspicion among some that black coaches are not

\footnotetext{
1 These salary figures are taken from the USA Today web site-http://www.usatoday.com/sports/nba/stories/2001-02-salaries.htm), while other player information is taken from The Sporting News Official NBA Register, 2001-2002 Edition.

${ }^{2}$ I examine the impact of black GMs below.
} 
treated as well as white coaches. For example, Smith (2004) suggests that black NBA coaches are held to a higher standard than white coaches, who in his opinion are given more power and authority over their players. In addition, he claims that white coaches earn more money than black coaches. An implication in his view and in the view of some players, is that NBA players are more likely to respect the decisions of white coaches than black coaches because of the power management gives the coaches. These arguments suggest that not only are black coaches more likely to be discharged than white coaches for a given performance level; in addition, white coaches are likely to get better performance out the players than black coaches.

These journalistic accounts of the NBA, coaching, and race yield very different pictures of the progress (or lack of progress) on this racial front. In this paper, I examine these issues statistically in order to determine what the overall pattern and practice of the league is. For example, I use performance data for the 1996-2003 period to implement a hazard function analysis of the job retention of black and white NBA coaches. I find very small and statistically insignificant racial differences in the separation hazard, all else equal. Moreover, I find statistically insignificant racial differences in quitting or discharge using a competing risks analysis.

These results do not suggest any discrimination with respect to retention. Of course, there still could be hiring discrimination. It is hard to find data on potential candidates for NBA jobs, as one would need in order to estimate the impact of race on the probability of a job offer. However, I am able to examine performance differentials among black and white coaches who are at the margin of being hired or retained by the league, by using quantile regression analysis. I find no racial differentials in performance among this group, controlling for qualifications, suggesting that black and white coaching candidates are held to the same entry standard. While we still don't know the qualifications of potentially discouraged black applicants, these findings do not suggest unequal treatment of equally qualified white and African American NBA coaches. 
Finally, even if it is true that there are no race differences in hiring or retention standards, it is still possible that teams practice salary discrimination. In fact with an appropriate "discrimination coefficient" making black coaches cheaper than white coaches of the same ability, hypothetically discriminatory teams can be induced to implement racially neutral hiring and retention standards with respect to coach quality. Therefore, I also analyze the determinants of coaching compensation. I find that although white coaches earn significantly more money than black coaches, when I control for experience and past coaching performance, the racial compensation gap disappears. Overall, then, these findings do not suggest the existence of employment discrimination against black coaches in the NBA.

\section{Relationship to Previous Research on Racial Discrimination in Coaching}

Research by economists on racial discrimination in coaching professional sports is very sparse, perhaps reflecting the relatively recent entry of nonwhite coaches into the professional ranks. Scully (1989), for example, noted that in the 1980s there were very few nonwhite baseball managers (a situation that persists somewhat today-see above). He attributed this to the fact that in baseball, a disproportionate share of managers played middle infield positions, and these were disproportionately white. It was not clear whether there was hiring or retention discrimination against nonwhite managers, controlling for qualifications or performance. And well known comments by a white baseball executive in 1987 claiming that blacks did not have the capability to become managers may have reflected prejudicial attitudes at the time (Staudohar 1996, p. 54).

More recently, Madden (2004) studied the issue of employment discrimination against black NFL coaches during the 1990-2002 period. Black coaches were very scarce during this period, as only 29 of 375 full team-seasons (7.7\%) involved a black head coach, and only 5 of the $82(6.1 \%)$ coaches during this period were black. In a sport 
where $67 \%$ of the players in 2001 were black (Madden 2004, p. 7), this low representation among coaches should raise some suspicions. Moreover, black coaches had statistically significantly better team performance than white coaches, controlling for team quality, suggesting barriers to the hiring of black coaches, although as discussed at length below, such a conclusion may or may not warranted. This ambiguity arises because average racial performance differentials are not necessarily informative about the existence of discriminatory hiring standards. Finally, controlling for current team performance and seniority, black coaches were significantly more likely to be fired than white coaches. These findings together led Madden (2004) to conclude that there was discrimination against African American NFL coaches in both hiring and retention. Perhaps in response to the dearth of black head coaches and threatened legal action, the NFL instituted in December 2002 a policy in which each team hiring a new head coach must interview at least one minority person; and one team has been fined $\$ 200,000$ for failure to observe this policy (Maske and Shapiro 2004).

This paper advances our knowledge of discrimination in managerial labor markets in several ways. First, it is the only research that studies racial differences in head coaches' pay in any sport. ${ }^{3}$ We wish to know whether there is unequal pay for equal work among professional coaches. Second, I estimate the impact of coach's race on retention probabilities, conditional on performance and qualifications. I use a hazard function approach that treats each coaching spell as an observation, and I allow for a relatively flexible relationship between tenure and the exit hazard. In contrast, Madden (2004) used a probability analysis in which each coach-year was treated as an independent observation. The hazard function approach is preferable on theoretical grounds in that it recognizes the link across years within a coaching spell, although my

\footnotetext{
${ }^{3}$ In a study of college basketball coaches' salaries, Humphreys (2000) finds that, all else equal, there are no statistically significant gender differences in head coaches' pay.
} 
results are not sensitive to whether one takes a hazard function approach or uses a probability analysis.

In addition to studying exits overall, I analyze quits and discharges as competing risks, although some models of turnover suggest that these are the same event. Specifically, if a match is less productive than the alternatives, then the efficient outcome is an exit, regardless of whether it is called a quit or a discharge. Moreover, it may be difficult to determine who is really responsible for a separation. For example, a worker may quit after being poorly treated by the firm. On the other hand, Hall and Lazear (1984) argue that under information asymmetries (with respect to the worker's in-firm productivity and the worker's outside options), quits are not the same as discharges. In light of this ambiguity over the distinction between quits and discharges, I perform one analysis of treating quits and discharges as the same event (i.e. separation is the hazard) as well as one analysis treating them distinctly (i.e., quits and discharges are each competing risks).

Third, like Madden (2004), I study performance differentials between black and white coaches. However, in order to make conclusions about entry discrimination, it is necessary to focus on coaches who are at the margin of entry into or exit from the league rather than average coaches, while Madden (2004) focuses primarily on average performance differentials. We wish to know whether the league has a higher entry quality standard for black than for white coaches. Average performance differentials between white and black coaches may be uninformative about whether there is hiring discrimination of this type.

Two simple examples will illustrate this point. In both cases, suppose that there are two black and two white coaches and that we can measure their quality on a cardinal scale. In the first case, let the two white coaches have quality levels of $q$ and $2 q(q>0)$, and let the two black coaches have quality levels of $q$ and $3 q$. And let $q$ be the minimum league standard for hiring a coach, which in this example is the same for black and white 
candidates. In this case, the average white coach will have quality $1.5 \mathrm{q}$, and the average black coaching quality is $2.0 \mathrm{q}$. Using average performance differentials would suggest hiring discrimination against black coaches. However, such a conclusion would be incorrect if $\mathrm{q}$ is the minimum hiring standard of quality the league accepts regardless of race, as assumed in this example. At the margin, where the hiring decision is made, whites and blacks are equally qualified in this example. ${ }^{4}$

In the second example, let the white coaches' quality be $q$ and $3 q$ and the black coaches' quality be $2 q$ and $2 q$. In this case, black and white coaches have the same average quality, and an analysis based on average quality will conclude that there is no hiring discrimination. However, if the minimum quality white and black coaches are both at the margin of entry, then the league in this case has a tougher standard for black than for white candidates. Thus, focusing on average quality or performance may cause us to erroneously attribute discrimination in hiring or to incorrectly conclude that there is no hiring discrimination. In both of these examples, focusing on the marginal coaches allows us to make the correct inference.

Madden (2004) acknowledges the problem that focusing on average racial performance differentials may not be informative about hiring discrimination. She notes that the most successful NFL coaches are white and that blacks still outperform whites on average. This pattern leads her to infer that blacks are better than whites at the margin. While this conclusion seems likely, it is still possible that performance is the same at the margin. Suppose there are three white coaches with quality levels q, 2q, and 12q, and three black coaches with quality levels q, 8q, and 9q. And assume again that the minimum entry requirement is a quality level of $\mathrm{q}$ for both white and black candidates. The best white coach is better than the best black coach, but the average black quality

\footnotetext{
${ }^{4}$ This point about the conceptual difficulties in using racial differences in average performance levels as an indicator of discrimination in hiring was first made in the sports context in Pascal and Rapping's (1972) study of baseball players. A similar point has been made about racial differences in average test scores and reverse discrimination in college admissions (Dickens and Kane 1999).
} 
(6q) is greater than the average white quality (5q) as found by Madden (2004). However in this numerical example, white and black coaches at the margin have the same quality, and the league's entry standard is non-discriminatory. It is therefore possible to observe what Madden (2004) finds for NFL coaching performance and for the same hiring standard to apply for white and black coaches. Of course, her retention analysis does suggest a form of employment discrimination against black NFL coaches, and it is still possible that there are higher entry standards for blacks.

The numerical examples just discussed show that it is essential in examining hiring discrimination to study coaches at the margin of entry or exit. In this paper I directly look at performance differentials at the margin by estimating quantile regressions with a performance indicator (current winning percentage) as the dependent variable. Specifically, I estimate the extent of racial performance differentials at the $10^{\text {th }}$ percentile of the conditional distribution (with respect to qualifications) of performance. That is, I ask whether controlling for qualifications, there are significant race performance differences near the bottom of the distribution, a location presumably at the margin of entry into or exit from the job. A complete analysis of hiring discrimination would focus on offer probabilities as a function of qualifications, and data needed to perform such analyses are not available. However, by using quantile regressions, we can make conclusions about performance differentials at the margin.

\section{Data and Empirical Procedures}

To study retention and performance differentials by race, I use The Sporting News Official NBA Guide and The Sporting News Official NBA Register, 1996-7 though 2003-4 editions. These sources have information on coaches' careers as well as current team success and other team characteristics. I supplement this information with data on team payroll, taken from Professor Rodney Fort's website: 
(http://users.pullman.com/rodfort/PHSportsEcon/Common/OtherData/DataDirectory.htm

1).

To study retention, I perform a survival analysis for each of several definitions of a "failure": i) failure is a separation; ii) failure is a quit; iii) failure is a discharge. I assume a log logistic accelerated failure time model, which has the following functional forms for survival time and the density of failure time:

$$
\begin{aligned}
& \text { 1) } S(t)=\left[1+(\lambda t)^{1 / \gamma}\right]^{-1} \\
& \text { 2) } f(t)=\left\{\gamma^{-1}\left(1+(\lambda t)^{1 / \gamma}\right\}^{-2}\left[\lambda^{1 / \gamma} t^{1 / \gamma-1}\right]\right.
\end{aligned}
$$

\section{3) $\lambda=\exp (-X B)$,}

where $\mathrm{S}$ is the probability of survival, $\mathrm{t}$ is current tenure, $\gamma$ is an incidental parameter to be estimated, $\mathrm{f}(-)$ is the density of failure time, $\mathrm{X}$ is a vector of explanatory variables to be discussed below (including coach's race), and B is a vector of coefficients.

The hazard model in equations 1)-3) has the appealing property that the impact of tenure on the separation (or quit or discharge) hazard is allowed to change in a relatively flexible way over the life of a coaching spell. For example, depending on the value of the estimated parameter $\gamma$, this model admits the possibility of non-monotonic exit hazards with respect to tenure, although monotonic and even constant hazards are also possible. ${ }^{5}$ For example, early in a coach's employment spell, exit may be rare as he is a given a chance to develop the team. The hazard may then rise as the front office begins to hold the coach responsible for current results. However, the hazard is likely to eventually fall, as the bad matches are ended. The model in equations 1)-3) allows such a process to play

\footnotetext{
${ }^{5}$ Farber (1999), for example, notes that in the National Longitudinal Survey of Youth (1979-91) data, when the time is measured monthly, the hazard rate for exit first rises and then falls with tenure.
} 
out, although my basic race results were not sensitive to the use of alternative hazard models, including ones that restrict the hazard function to be monotonic.

The explanatory variables in X include the coach's race (a dummy variable equaling 1 for white coaches), current season's team performance (winning percentage), the log of the team's real payroll relative to the league average for a given year, the coach's age and age squared, years of NBA head coaching experience and its square, years of college head coaching experience, years of professional head coaching experience other than the NBA (e.g. the Continental Basketball Association, a minor league), years spent as an assistant coach in the NBA, lifetime NBA head coaching winning percentage (zero for rookie coaches), number of years in the NBA playoffs as head coach (zero for rookie coaches) years of NBA or American Basketball Association (ABA) playing experience, number of NBA or ABA allstar teams to which one was named as a player, and year dummies. ${ }^{6}$

The variables in $\mathrm{X}$ are chosen to measure current performance and qualifications of the coach. Current team winning percentage is the most straightforward performance measure, although I also experimented with current success in the playoffs as an alternative measure with no change in the results. ${ }^{7}$ I include team payroll (relative to other teams) as a way of controlling for expected player quality. I anticipate that standards will be higher for coaches that are in charge of higher payroll teams. Several of the other variables are detailed controls for the type of coaching experience as well as coaching results. And the coach's NBA playing performance may reflect additional value to management beyond one's coaching ability. Finally, note that the impact of tenure on the separation hazard will be estimated through the $\gamma$ parameter. The

\footnotetext{
6 The ABA was a rival professional league in existence from 1967 to 1976, which was partially absorbed into the NBA in 1976 (Staudohar 1996).

7 Specifically, I created five dummy variables that each refer to a successive round reached in the playoffs. Reaching the "fifth" round in this case means that the team won the championship, while a zero for all five dummies means that the team did not make the playoffs.
} 
asymptotic standard errors are corrected for the correlation across spells for the same coach. I also experimented with corrections for correlation across observations for the same team on the theory that the same management is making the decision, although the results were not changed.

To estimate performance differentials, I use current winning percentage as the dependent variable and $\mathrm{X}$ as a vector of explanatory variables (in some cases augmented by current tenure) in quantile regression analyses. For reasons discussed earlier, I will be focusing on the $10^{\text {th }}$ percentile of the conditional performance distribution, although I also experimented with other quantiles. This analysis of course assumes a recursive structure where performance is determined and then the retention decision is made. The asymptotic standard errors are computed using a bootstrapping procedure.

Finally, to study compensation differentials between black and white coaches, I use an annual survey of NBA coaches' contracts, supplied by Richard Walker of The Gaston Gazette. Walker has constructed this data base using interviews with coaches' agents, reporters for other newspapers and the coaches themselves. The data include contracts signed between 1997 and 2004 and are complete for all coaches during the 2000-1 through 2003-4 seasons. Although I use all of the data available during the 19972004 years, my results are unchanged if I use only the complete data for these latter four seasons.

An essential feature of the coaches' compensation data base is that we have information on the total compensation (including bonuses), the guaranteed duration, and the signing date of each coach's contract. Knowing the total contractwide compensation allows one to construct a more accurate measure of average annual pay than if one has data only on current salary, due to the pro-rating of bonuses. In addition, it is likely that a coach would not view a one year contract at $\$ 2$ million and a two year contract at $\$ 4$ million as equally attractive. The data used here allow one to distinguish between such cases, while data sources that merely provide current salary do not. Finally, and perhaps 
equally importantly, knowing when each coach signed his current contract allows me to determine the productivity and qualifications data that were known at the time the contract was signed. For example, during the 2003-4 season, the Los Angeles Laker coach Phil Jackson, who was the team's coach during three consecutive championship seasons (1999-2000 through 2001-2), was under a contract signed before this run of championships had occurred.

I analyze three dependent variables that are all indicators of compensation: $\log$ average annual compensation; log total contractwide compensation; and contract duration in years. They are analyzed as functions of race and the qualifications variables mentioned earlier: age, age squared, NBA head coaching experience and its square, college head coaching experience, other professional head coaching experience, NBA assistant coaching experience, lifetime NBA head coaching winning percentage (equal to zero for rookie coaches), number of years in the NBA playoffs as a head coach, number of years as an NBA player, and number of years as an NBA allstar player.

\section{Results}

Figure 1 and Tables 1 and 2 provide some descriptive information on race, turnover, pay, performance and the explanatory variables over the sample period. ${ }^{8}$ Figure 1 shows that over the whole sample period, $72.6 \%$ of coach-team observations involved a white coach, counting a team twice in a given year if the team changed coaches during the season. This percentage is based on 219 observations on coach-years, with 60 of these involving black coaches $(27.4 \%)$ and 159 with white coaches $(72.6 \%)$. The actual number of white individual coaches was 46 (67.6\%), and there were 22 individual black coaches during this period (32.4\%). In addition, Figure 1 shows a dramatic increase in

\footnotetext{
8 In what follows, "1997" means the 1996-7 season, and so on.
} 
black representation starting in the 2000-2001 season. The level of black representation is much higher in the NBA than Madden's (2004) figures show for the NFL, where, recalling our earlier discussion, only $7.7 \%$ of coach-year observations involved a black coach, and only $6.1 \%$ of individual coaches were black. African-American representation in the NBA head coaching ranks is also higher even relative to the higher level of nonwhite player representation, which was $80 \%$ in 2001-2, as reported in (Kahn and Shah, 2003), and black representation in the NBA was 79\%. Recall that in 2001 , $67 \%$ of NFL players were black. Thus, black player representation is roughly $18 \%$ $(79 / 67=1.18)$ higher in the NBA, but the incidence of black coaches is $3-5$ times as high in the NBA as in the NFL. ${ }^{9}$

Table 1 shows the incidence of turnover, discharges, and quitting by race. The average levels of these dependent variables are very close for black and white coaches. In particular, $27 \%$ of white coaches and $28 \%$ of black coaches had a job separation in an average year, $18 \%$ of white coaches and $20 \%$ of black coaches were discharged on average, and $9 \%$ of white coaches and $8 \%$ of black coaches quit in an average year. Not surprisingly, none of these racial differences are even close to being statistically significant. Overall, black and white coaches have virtually identical levels of voluntary and involuntary turnover. However, since discrimination means unequal treatment of equally qualified workers, we need to condition on performance, as described above.

Table 1 also shows that white-coached teams on average have better records than black-coached teams. The overall difference of roughly 8 percentage points is statistically significant at the 3\% level taking into account the correlation of observations for a given coach. Again, we need to control for the inputs available to coaches in order to make conclusions about performance differentials.

\footnotetext{
9 Madden's (2004) NFL figures are for an earlier period (1990-2002) than my NBA sample (1997-2003). However, even using a recent year such as 2003, the black coaching incidence is about $10 \%$ in the NFL and $45 \%$ in the NBA. See http://www.espn.com .
} 
Table 1 contains data on one of the major inputs — team payroll. The most informative payroll variable is the relative team payroll, which measures the log of the ratio of the team's payroll to the league average for the given year. ${ }^{10}$ The relative payroll is roughly $5.4 \%$ higher on average for whites than blacks, a difference which is, however, only 1.1 times its standard error (taking into account the correlation of observations for a given coach). Thus, there is some weak suggestion that white coaches have more to work with than black coaches, an issue to which I return below.

Table 1 provides some descriptive information on the other major explanatory variables used in this study, stratified by race and then by race and rookie status. White NBA coaches have more head coaching experience both in the NBA and in college and other professional leagues than black NBA coaches. However, overall, black NBA coaches have more NBA playing experience and years spent as an NBA assistant coach. Recently, the assistant coach pattern has changed, as black rookie coaches have actually spent fewer years as an NBA assistant coach, as well as fewer college coaching and nonNBA professional coaching years, than rookie white coaches. Moreover, black rookies are almost two years younger on average than white rookies. These patterns for rookie coaches, as well as the sharp increase in black representation starting in 2000-1 (see Figure 1), suggest some accelerated movement into the NBA head coaching ranks for African-Americans.

Table 2 contains compensation information for head coaches. It is based on a sample of 90 coach-contract observations, with exactly 70\% (63) white and 30\% (27) black. These observations cover 60 individual coaches, 40 of whom were white and 20 of whom were black. White coaches earn about $\$ 926,000$ more annually and have

\footnotetext{
${ }^{10}$ The raw average team payroll is actually a statistically insignificant $3 \%$ higher (about $\$ 1.35$ million) for black than white coaches; however, this discrepancy is due to the fact that the incidence of black coaches is disproportionately recent, when player real salaries have been higher. Controlling for year effects, white coaches have team payrolls that are a statistically insignificant $\$ 1.92$ million higher than black coaches' teams.
} 
contracts with $\$ 3.827$ million more guaranteed compensation than black coaches. Comparing the average log salary and log compensation, which coaches have an advantage of $0.331 \log$ points in annual salary and $0.353 \log$ points in total contractwide compensation. Controlling for year effects and taking into account correlation across contracts for the same coach, these differences in log salary and log compensation are statistically significant at the $2.4 \%$ level for salary and $9.9 \%$ level for compensation. Contract duration is slightly longer ( 0.233 years) for white coaches than black coaches, a difference that is not statistically significant, taking into account year effects and withincoach error correlation. Overall, white coaches are better-paid than black coaches, and below, I report results which allow us to determine whether these pay differentials remain when we control for coaches' qualifications and productivity.

Tables 3-5 contain parameter estimates from the analysis of turnover. As mentioned earlier, I use a survival analysis where failure is defined as exit (Table 3), discharge (Table 4), or quit (Table 5). In each case, a positive coefficient on a variable means that the variable raises the probability of survival. All three tables convey the message that there are no statistically significant racial differences in exit, discharge, or quit outcomes, regardless of what else we control for. Figures 2-4 provide some evidence on the magnitude of these effects by showing the black and white exit, discharge and quit hazards the model predicts when the other explanatory variables take on their mean values. In each case, I use the model with the full set of explanatory variables to make these calculations. In each instance, the hazard first increases with tenure, then falls. This pattern is consistent with the idea that early in a coach's tenure, the team is collecting information on his performance, so the exit hazard is relatively low. ${ }^{11}$

Figure 2 shows that at each period, the overall exit hazard is virtually identical for white and black coaches, controlling for the other explanatory variables. Figures 3 and 4

\footnotetext{
${ }^{11}$ As noted earlier, Farber (1999) finds a similar pattern for workers in general, at least when the hazard is allowed to vary on a monthly basis.
} 
show that this finding is the result of offsetting racial differences in the discharge and quit hazards. On the one hand, Figure 3 shows modestly smaller discharge hazards for black coaches, all else equal, while Figure 4 shows substantially larger quit hazards for black coaches. However, it is important to remember that all of these effects are statistically insignificant and that the total exit hazard is virtually identical by race. Moreover, there is no evidence that black coaches are discharged with any greater probability than white coaches.

Several other interesting findings emerge from the hazard function analysis. First, higher team winning percentage significantly lowers the exit and discharge hazards, and has a negative effect on quitting that is 1.45 times its asymptotic standard error. Not surprisingly, coaches are less likely to leave or be released from winning teams. Second, the team's relative payroll level significantly raises the overall exit probability and the quit probability, with positive but insignificant effects on the discharge probability. Nonetheless, these findings suggest that in deciding whether a given coach is a good match, the parties take into account both the outcome (winning percentage) and the raw material the coach is given to work with (the relative payroll level). Third, controlling for current success, coaches with higher lifetime winning percentages are significantly less likely to separate, another intuitive finding. Finally, previous playing experience or star power appears to have no impact on coaching turnover.

Table 6 contains ordinary least squares (OLS) and quantile regression results (quantiles .10 and .90) for the determinants of current team winning percentage. The first model in each panel shows the corresponding racial difference in winning percentage controlling only for year dummies. Table 6, Panel A shows the OLS results, and white coaches have statistically significant (at the $2.2 \%$ level on a two tailed test) 0.0788 better winning percentage than black coaches overall, where the dependent variable ranges from 0 to 1 . This is a sizable difference, equivalent to about $46 \%$ of the standard deviation of winning percentage across coach-year observations. Does this effect mean that there is 
reverse discrimination against white coaches? The quantile regression at the $10^{\text {th }}$ percentile of the conditional winning percentage distribution suggests that this is not the case. Specifically, Table 6, Panel B shows that the white effect is only 0.0324 and is only about $73 \%$ of its asymptotic standard error. Without controlling for any coach or team characteristics, it appears that marginal white and marginal black coaches have similar winning percentages in the NBA, on the assumption that those with the lowest winning percentages are the marginal coaches. This is a reasonable assumption, since the hazard functions showed that higher current winning percentage reduced the exit hazard, all else equal. Table 6, Panel C shows a 0.1098 white effect at the $90^{\text {th }}$ percentile, a large impact that is statistically significant at better than the $1 \%$ level. These inframarginal white coaches have much better winning percentages than inframarginal black coaches. This coefficient is the same size as the difference between the winning percentage at the $75^{\text {th }}$ percentile (.609) and .5 , or a median team.

The other models in Table 6 successively add team relative payroll and then the other explanatory variables to the performance regressions. When I add only relative payroll, the OLS white effect falls to 0.0647 and remains significant (at the $6.3 \%$ level), the impact at the $10^{\text {th }}$ percentile rises to 0.0594 and is marginally significant (at the $11.2 \%$ level), and the effect at the $90^{\text {th }}$ percentile falls to 0.0818 and is significant at the $0.6 \%$ level.

The third model in each of Table 6, Panels A-C adds coaching and playing experience variables. The OLS and .10 quantile white effects both rise slightly in magnitude (to 0.0678 and 0.0638 respectively), the OLS estimate remains significant (at the $7.6 \%$ level), and the .10 quantile white effect standard error rises to a level slightly larger than the coefficient. In this specification, the .90 quantile white effect falls to 0.0696 but remains significant (at $2.5 \%$ ).

In the first three specifications of Table 6 , there is no evidence that black coaches at the margin face a higher entry hurdle than white coaches. In each case, the white 
effect at the $10^{\text {th }}$ percentile is positive and only marginally significant once. The last specification adds past coaching success to the list of explanatory variables: lifetime winning percentage and years in the NBA playoffs as a head coach. In this specification, the average white effect (OLS) falls to 0.0328 and is about the same size as its asymptotic standard error; the impact at the $10^{\text {th }}$ percentile actually becomes negative, an effect consistent with lower hiring standards for white coaches, but is only 1.04 times its asymptotic standard error in absolute value; and the impact at the $90^{\text {th }}$ percentile falls again to 0.0614 and is only 1.50 times its asymptotic standard error in absolute value. The impact at the $10^{\text {th }}$ percentile, while insignificant, is consistent with the existence of a higher entry hurdle for black coaches; however, we are controlling for past NBA performance in this regression. Therefore we are not estimating the full effect of race on performance at the bottom of the distribution. The model not controlling for lifetime NBA performance does this and shows an insignificantly positive white effect at the $10^{\text {th }}$ percentile.

Table 7 takes a closer look at coaches who may be at the margin of retention or hiring by estimating the basic winning percentage regressions with the sample restricted to coaches with three years or less current tenure. These are all somewhat recently hired coaches, and if there are differential hiring standards for black and white coaches, such policies should have their largest effects on a group of coaches relatively new to their teams. The racial differences in winning percentage among this subgroup are all smaller in absolute value than in the full sample of coaches. In fact, the only statistically significant racial effect in Table 7 is the positive white effect at the $90^{\text {th }}$ percentile with only year dummies as covariates, which is 0.0854 and is significant at the $0.3 \%$ level. The most direct test of differential performance standards, which is the white effect at the $10^{\text {th }}$ percentile, shows coefficients ranging from -0.0350 to +0.0371 , which are always well below their asymptotic standard errors in magnitude. 
The basic findings for separation hazards and coaching performance were robust to the inclusion of several additional controls. For example, controlling for the race of the general manager, the racial composition of the team, and the interactions of these variables with the race of the coach did not change the conclusions that there were no statistically significant racial performance or exit hazard differences. Moreover, the racial composition of the team and the race of the general manager had no significant interaction effects with the coach's race in any of the analyses. In addition, when I controlled for the tenure and its square in analyses of performance, my conclusions about race were unchanged. The basic performance specifications omit tenure on the grounds that this is likely to be endogenous with respect to performance.

These turnover and performance analyses, while suggestive, do not prove that the NBA does not discriminate against black coaches. Suppose, for example, that there are discriminatory salary differentials which reflect owner tastes. Then it is possible that the owners view black and white coaches as equivalently-desirable workers at the margin, where a black salary shortfall compensates owners for their disutility. Tables 8-10 address these issues by showing the results of the analysis of racial differences in coaches' compensation. Table 8 shows that when I control only for year effects that white coaches earn higher annual compensation than black coaches by 0.3276 log points, an effect that is significant at the $2.4 \%$ level. However, controlling for age and NBA head coaching experience (and their squares), the point estimate falls to 0.1686 log points and is not significant, although it is 1.54 times its standard error. But when I add the full set of productivity and qualifications controls, the white effect becomes -0.0293 , a very small impact in absolute value that is only 0.31 times its standard error in absolute value. Table 9 tells largely the same story for total guaranteed compensation: again, controlling for measured productivity, there are only small and statistically insignificant racial 
compensation differentials. And Table 10 shows that the racial effects on contract duration are very small and never statistically insignificant. ${ }^{12}$

While the results in Tables 8-10 suggest that black coaches do not face discrimination in compensation, it is noteworthy that this conclusion is reached only after I control for a series of productivity-related covariates. If these variables were themselves the result of discrimination, then it is possible that the large and statistically significant overall racial salary and compensation differentials represent the true extent of employment discrimination. However, several findings cast doubt on this latter interpretation. First, consider for example the reduction in the race effect in Tables 8 and 9 caused by adding age and coaching experience. My earlier results on turnover and performance differentials at the margin suggest that NBA coaching experience is not a "tainted" variable (i.e. one that reflects discrimination).

Second, it is possible that one's lifetime NBA coaching record reflects access to highly paid players over one's career. If this access reflects discrimination, then it may not be appropriate to control for one's coaching record. In this regard, it is interesting to note that in Tables 8-10, even when I don't control for past NBA coaching success, the racial salary, compensation and contract duration effects are small and insignificant, although the point estimates for salary and compensation show positive effects for being white. Moreover, in the analysis of turnover and current performance at the margin, excluding past NBA success does not affect the conclusion that there are statistically insignificant racial exit and performance differences. And analyzing current relative payroll (i.e. payroll relative to the league average) as a dependent variable shows no significant racial differences in team payroll. For example, controlling only for year effects, white coaches have a $0.0568 \log$ point higher team payroll, an effect that is only 1.2 times its standard error. Controlling additionally for age, and NBA and other

\footnotetext{
${ }^{12}$ I use ordinary least squares (OLS) in analyzing contract duration because the more theoretically appropriate ordered probit or ordered logit analysis would not converge.
} 
coaching experience, white coaches have only a $0.0370 \log$ point higher payroll than black coaches, an effect that is only 0.64 times its standard error. These supplementary analyses do not suggest that black and white coaches have unequal access to high payroll teams.

Overall, my findings do not suggest the existence of employment discrimination against black NBA coaches, in contrast to the evidence Madden (2004) presents which is consistent with discrimination against black NFL coaches. There has traditionally been less positional segregation in basketball than football, and black players have been more represented in the leadership role of point guard in basketball than quarterback in football (Kahn 1991; Kahn and Shah 2003). In my sample of NBA coaches, 42 of 68 (about $62 \%$ ) coaches had NBA or ABA playing experience, with $86 \%$ of black coaches and $50 \%$ of white coaches having been NBA or ABA players. More importantly, among these 42 coaches with major league playing experience, fully 30 , or $71 \%$, of them played guard in the NBA or ABA. Both black and white NBA coaches with this major league playing experience were very likely to have played guard: 15 of $23(65.2 \%)$ white coaches and 15 of $19(78.9 \%)$ black coaches with NBA or ABA playing experience were guards. And according to Kahn and Shah's (2003) data, as of 2001-2, 45.5\% of black NBA players but only $20.5 \%$ of white NBA players were guards. Moreover, since $79 \%$ of the players were black, this means that there were 8.8 times as many black guards as white guards in the NBA. These data together suggest that the pipeline for NBA coaches, a substantial portion of which consists of NBA or ABA guards, has ample black representation.

In other sports, the pipeline from player to coach seems less favorable to African Americans than basketball. First, in the NFL, only 12 of the 32 head coaches in 2002 had NFL playing experience, and assigning each NFL coach his NFL or college position (if he didn't play in the NFL), Madden (2004) did not find that particular positions were overrepresented among head coaches. Second, in baseball, I have noted Scully's (1989) 
findings that managers were especially likely to have been middle infielders, and this position, at least at the time he was writing, was disproportionately white.

An additional possible explanation for differences between the NFL and the NBA is that the pipeline may be longer in the NFL than in the NBA, where often players retire and soon become assistant coaches or even head coaches in the NBA. If so, then not only will there be more black candidates relative to black player representation in the NBA than the NFL; the shorter pipeline also allows management policies of nondiscrimination to have effects more quickly.

\section{Conclusions}

In this paper, I have used NBA data for the 1997-2003 period to estimate racial turnover, performance and pay differentials among head coaches in an attempt to determine whether there is employment discrimination against black coaches. Controlling for performance and qualifications, I found no statistically significant race differences in the overall probability of exit, quitting or discharge. Moreover, the point estimates for the impact of race on the exit hazard were very small in magnitude. There were also no statistically significant or quantitatively large racial performance differentials among those who are likely to be at the margin of entry or exit into the league. And controlling for coach qualifications, there were only small and statistically insignificant racial differences in coaches' annual compensation, total contractwide guaranteed compensation, and contract duration.

Taken as a package, these results do not suggest the presence of retention, hiring or wage discrimination against current black NBA coaches. However, we have no information on rejected coaching candidates or, perhaps more importantly, potential candidates who may have been discouraged from applying for the job. Moreover, it is still possible that white potential coaching candidates have greater access to a network of 
coaching opportunities than black potential candidates even in the absence of explicit racial discrimination on the part of top management. But the results in this paper suggest that once in the league, white and black coaches appear to be equally treated and that the marginal black coaches have about the same performance as marginal white coaches. And I also found that a disproportionate share of NBA coaches played guard at the major league level. Since black players are more than twice as likely to play guard as white players are and since there are roughly four times as many black players as white players in the NBA, the pipeline has many potential black coaching candidates. In the long run, one might expect a nondiscriminatory league to have a larger share of black coaches than black players. 


\section{References}

Dickens, William T. and Thomas J. Kane, "Racial Test Score Differences as Evidence of Reverse Discrimination: Less Than Meets the Eye," Industrial Relations v38, n3 (July 1999): 331-63.

Farber, Henry S., "Mobility and Stability: the Dynamics of Job Change in Labor markets," in Orley Ashenfelter and David Card, eds., Handbook of Labor Economics, volume 3B (Amsterdam: Elvesier, 1999), pp. 2439-2483.

Hall, Robert E., and Edward P. Lazear, "The Excess Sensitivity of Layoffs and Quits to Demand," Journal of Labor Economics 2:2 (April 1984): 233-257.

Humphreys, Brad R., "Equal Pay on the Hardwood: The Earnings Gap between Male and Female NCAA Division I Basketball Coaches," Journal of Sports Economics 1:3 (August 2000): 299-307.

Kahn, Lawrence M. 1991. "Discrimination in Professional Sports: A Survey of the Literature," Industrial \& Labor Relations Review. 44:3 (April), pp. 395-418.

Kahn, Lawrence M. and Malav Shah, "Race, Compensation and Contract Length in the NBA: 2001-2," working paper, Cornell University, September 2003.

Madden, Janice Fanning, "Differences in the Success of NFL Coaches by Race, 19902002: Evidence of Last Hire, First Fire," Journal of Sports Economics 5:1 (February 2004): 6-19.

Maske, Mark and Leonard Shapiro, "Minority Hiring is Lauded," Washington Post, January 22, 2004, p. D01, accessed at http://www.washingtonpost.com/ac2/wpdyn/A36882-2004Jan21 ?language= printer , January 23, 2004.

Pascal, Anthony H. and Leonard A. Rapping, "The Economics of Racial Discrimination in Organized Baseball," in A. H. Pascal, ed., Racial Discrimination in Economic Life (Lexington, MA.: DC Heath, 1972), pp. 119-156.

Rhoden, William C., "Power is Colorblind in NBA," International Herald Tribune, February 4, 2004, accessed at http://www.iht.com/articles/128027.html, 3/22/04.

Scully, Gerald R., The Business of Major League Baseball (Chicago: University of Chicago Press, 1989).

Smith, Stephen A., "Players Fail to Give Best to Black Coaches," Philadelphia Inquirer, February 10, 2004, accessed at http://www.philly.com/mld/inquirer/sports/7915355.htm, 3/22/04.

Staudohar, Paul D. 1996. Playing for Dollars: Labor Relations and the Sports Business. Ithaca, NY: Cornell University Press.

The Sporting News. Official NBA Guide. Annual Issues 1996-7 through 2002-3. St. Louis: The Sporting News.

The Sporting News. Official NBA Register. Annual Issues 1996-7 through 2002-3. St. Louis: The Sporting News. 
Figure 1: Fraction of NBA Coaches Who Were White, 1997-2003

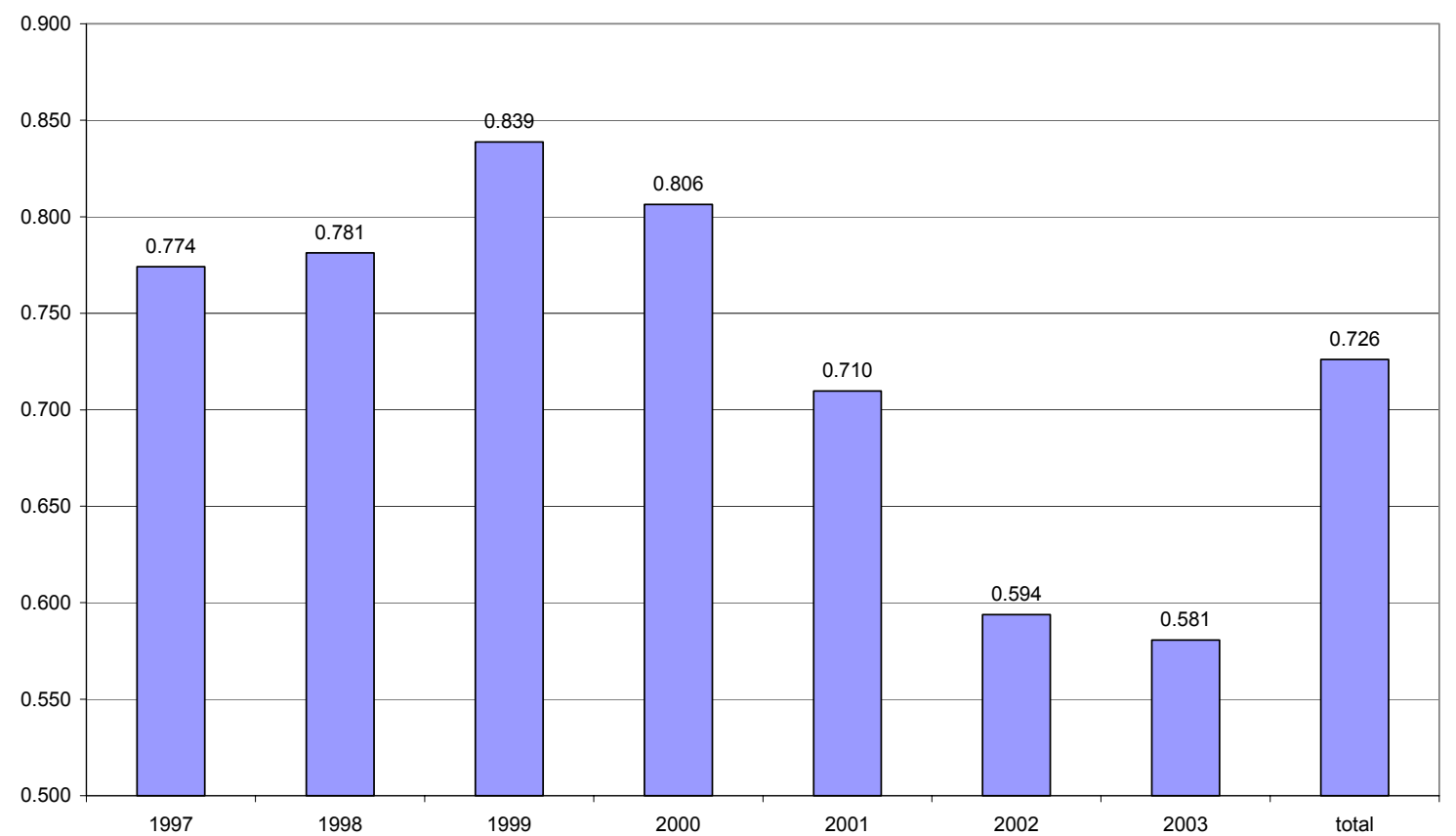




\section{Figure 2: Effect of Race on the Exit Hazard}

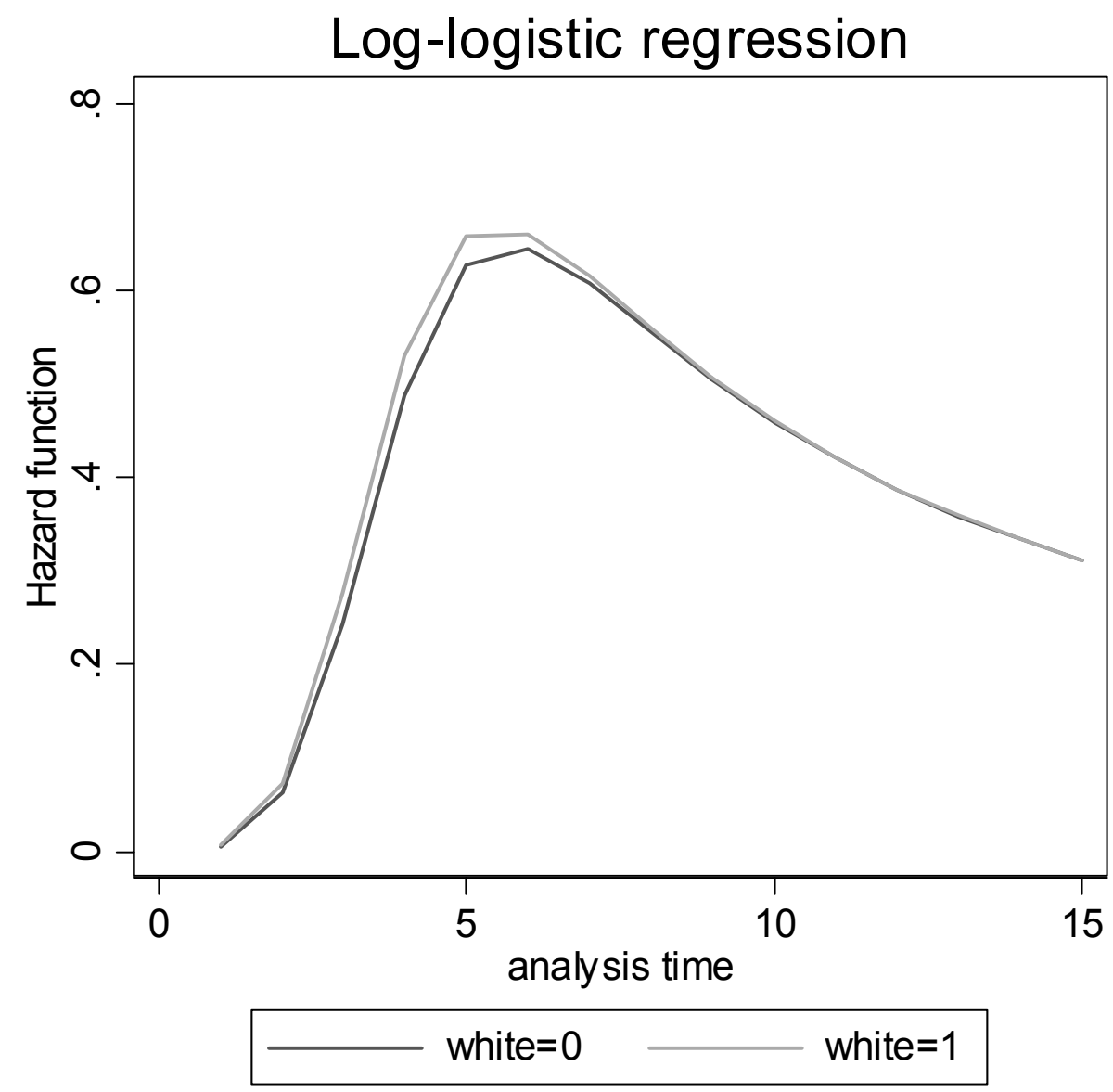

Note: analysis time is in years. Estimates based on survival model from Table 2 with all covariates included and set at their mean values. Failure is defined as exit. 


\section{Figure 3: Effect of Race on the Discharge Hazard}

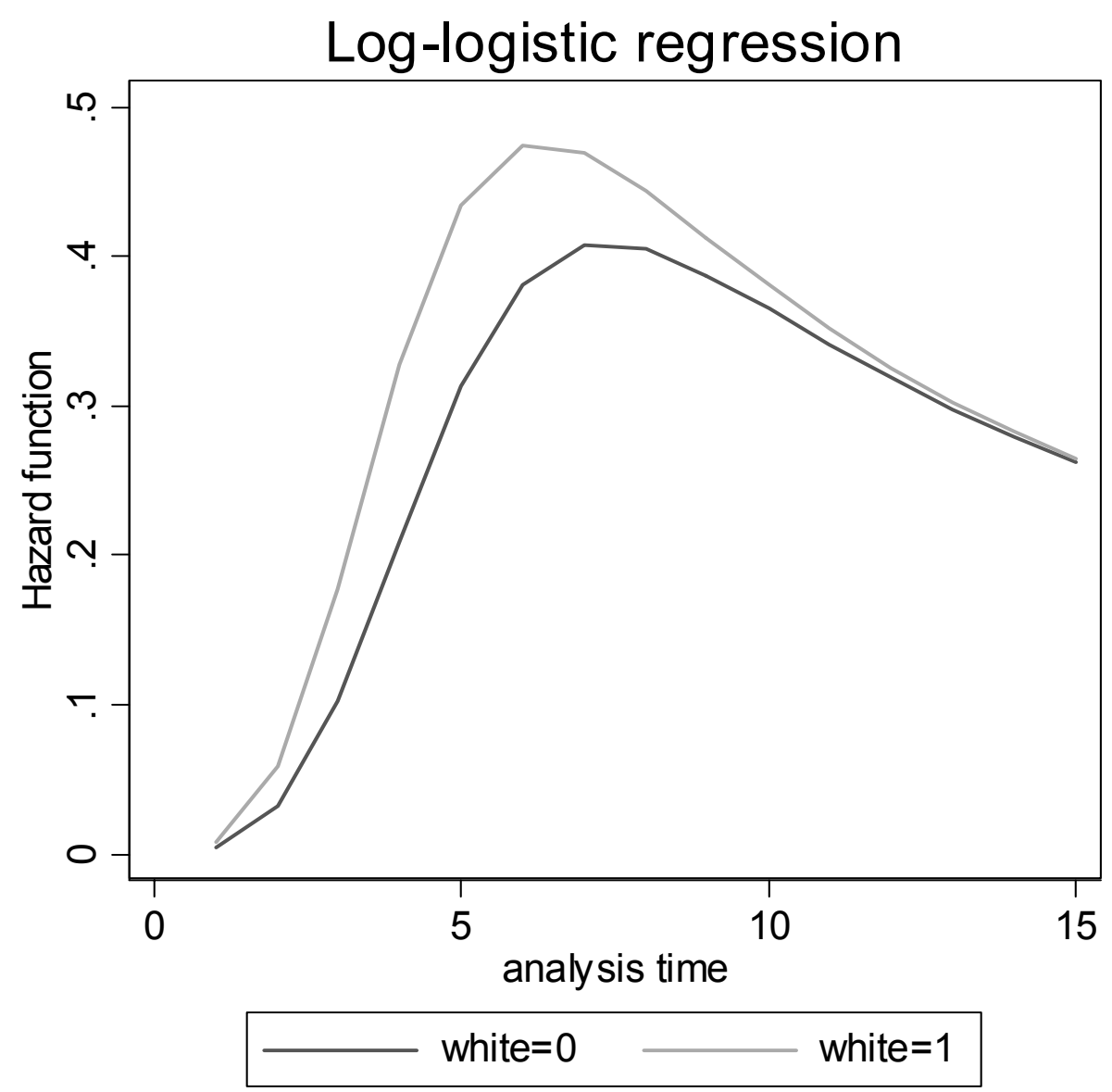

Note: analysis time is in years. Estimates based on survival model from Table 3 with all covariates included and set at their mean values. Failure is defined as discharge. 
Figure 4: Effect of Race on the Quit Hazard

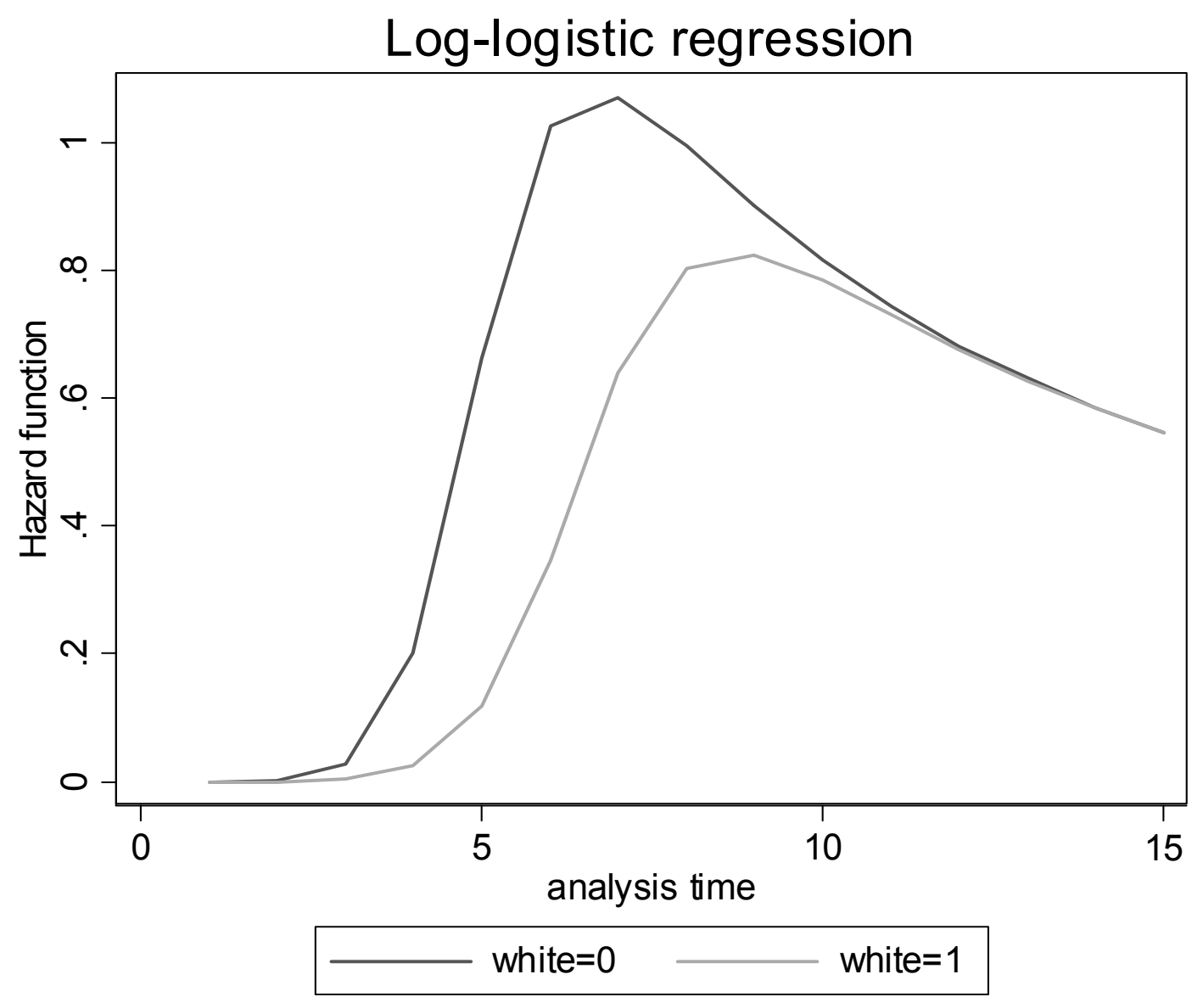

Note: analysis time is in years. Estimates based on survival model from Table 4 with all covariates included and set at their mean values. Failure is defined as quit. 


\section{Table 1: Means of Selected Variables by Race: Turnover Analysis}

\begin{tabular}{|c|c|c|c|c|c|c|}
\hline & \multicolumn{2}{|c|}{ All Coaches } & \multicolumn{2}{|c|}{ Rookie Coaches } & \multicolumn{2}{|c|}{$\begin{array}{c}\text { Coaches with NBA } \\
\text { Head Coaching } \\
\text { Experience }\end{array}$} \\
\hline & Whites & Blacks & Whites & Blacks & Whites & Blacks \\
\hline Turnover (quit or fired) & 0.27 & 0.28 & 0.14 & 0.15 & 0.28 & 0.32 \\
\hline Fired & 0.18 & 0.20 & 0.14 & 0.08 & 0.19 & 0.23 \\
\hline Quit & 0.09 & 0.08 & 0.00 & 0.08 & 0.10 & 0.09 \\
\hline Years NBA Head Coaching Experience & 7.43 & 5.25 & --- & ---- & 8.15 & 6.70 \\
\hline Current Tenure & 2.66 & 1.20 & ---- & ---- & 2.92 & 1.53 \\
\hline Years College Head Coaching Experience & 3.47 & 0.50 & 4.07 & 1.23 & 3.41 & 0.30 \\
\hline Years Pro Non-NBA Head Coaching Experience & 1.09 & 0.07 & 1.36 & 0.00 & 1.06 & 0.09 \\
\hline Current Age & 49.89 & 46.93 & 43.00 & 41.46 & 50.56 & 48.45 \\
\hline Years in NBA Playoffs as Head Coach & 5.53 & 2.65 & ---- & ---- & 6.06 & 3.38 \\
\hline Years as NBA Assistant Coach & 3.65 & 4.37 & 4.50 & 2.31 & 3.57 & 4.94 \\
\hline Years Played in NBA or ABA & 5.72 & 9.95 & 3.71 & 10.31 & 5.92 & 9.85 \\
\hline Years as NBA or ABA Allstar Player & 1.25 & 2.05 & 0.86 & 1.38 & 1.28 & 2.23 \\
\hline Current Team Payroll (millions of 2000 dollars) & 43.85 & 45.20 & 40.75 & 45.04 & 44.15 & 45.25 \\
\hline $\begin{array}{l}\text { Current Relative Team Payroll (log ratio of own to } \\
\text { league ave) }\end{array}$ & 0.02 & -0.04 & -0.06 & 0.01 & 0.02 & -0.05 \\
\hline Current Team Winning Percentage & 0.51 & 0.43 & 0.39 & 0.37 & 0.52 & 0.45 \\
\hline Career NBA Head Coaching Winning Percentage & ---- & ---- & ---- & ---- & 0.547 & 0.432 \\
\hline sample size & 159 & 60 & 14 & 13 & 145 & 47 \\
\hline
\end{tabular}

Note: Each data point is a coach-year observation. 
Table 2: Means of Compensation-Related Variables by Race

\begin{tabular}{lcc} 
& Whites & Blacks \\
\hline Annual Salary (millions) & & \\
Contractwide Compensation (millions) & $\$ 3.290$ & $\$ 2.364$ \\
Contract Duration (years) & $\$ 11.997$ & $\$ 8.170$ \\
Log (Annual Salary) & 3.492 & 3.259 \\
Log (Contractwide Compensation) & 1.036 & 0.705 \\
& 2.188 & 1.835 \\
sample size & 63 & 27 \\
\hline
\end{tabular}

Note: Each data point is a coach-year observation. Data are for contracts signed after 1997. 
Table 3: Determinants of Annual Coach Retention (log logistic hazard function, hazard=turnover)

\begin{tabular}{|c|c|c|c|c|c|c|c|c|}
\hline & Coef & $\begin{array}{l}\text { Asy Std } \\
\text { Err }\end{array}$ & Coef & $\begin{array}{l}\text { Asy Std } \\
\text { Err }\end{array}$ & Coef & $\begin{array}{l}\text { Asy Std } \\
\text { Err }\end{array}$ & Coef & $\begin{array}{l}\text { Asy Std } \\
\text { Err }\end{array}$ \\
\hline white coach & 0.2378 & 0.1789 & -0.0073 & 0.1661 & 0.0052 & 0.1531 & -0.0326 & 0.0982 \\
\hline Current Team Winning Percentage & ---- & --- & 2.9461 & 0.6722 & 3.4514 & 0.6690 & 1.7908 & 0.6381 \\
\hline $\begin{array}{l}\text { Current Relative Team Payroll (log ratio of own to } \\
\text { league ave) }\end{array}$ & ---- & ---- & ---- & ---- & -0.8070 & 0.4348 & -0.5341 & 0.2892 \\
\hline age & --- & --- & & & & 0.4040 & 0.1010 & 0.1316 \\
\hline age squared & & & & & & & -0.0013 & 0.0014 \\
\hline Years NBA Head Coaching Experience (exp) & ---- & ---- & ---- & ---- & ---- & ---- & 0.0397 & 0.0487 \\
\hline exp squared & ---- & ---- & ---- & ---- & ---- & ---- & 0.0005 & 0.0015 \\
\hline Years College Head Coaching Experience & ---- & ---- & ---- & --- & ---- & ---- & 0.0035 & 0.0192 \\
\hline Years Pro Non-NBA Head Coaching Experience & ---- & ---- & ---- & ---- & ---- & ---- & 0.0014 & 0.0489 \\
\hline Years as NBA Assistant Coach & ---- & ---- & ---- & ---- & ---- & ---- & 0.0068 & 0.0187 \\
\hline Career NBA Coaching Winning Percentage & ---- & ---- & ---- & ---- & ---- & ---- & 0.8161 & 0.4280 \\
\hline Years in NBA Playoffs as Head Coach & ---- & ---- & ---- & ---- & ---- & ---- & 0.0166 & 0.0520 \\
\hline Years Played in NBA or ABA & ---- & ---- & ---- & ---- & ---- & ---- & -0.0158 & 0.0190 \\
\hline Years as NBA or ABA Allstar Player & \multirow{2}{*}{\multicolumn{2}{|c|}{---- yes }} & ---- & ---- & ---- & ---- & -0.0161 & 0.0214 \\
\hline year dummies? & & & \multicolumn{2}{|c|}{ yes } & \multicolumn{2}{|c|}{ yes } & \multicolumn{2}{|c|}{ yes } \\
\hline Sample size (coach-year observations) & \multicolumn{2}{|c|}{219} & \multicolumn{2}{|c|}{219} & \multicolumn{2}{|c|}{219} & \multicolumn{2}{|c|}{219} \\
\hline Number of Coaches & \multicolumn{2}{|c|}{68} & \multicolumn{2}{|c|}{68} & \multicolumn{2}{|c|}{68} & \multicolumn{2}{|c|}{68} \\
\hline Number of Exits & \multicolumn{2}{|c|}{60} & \multicolumn{2}{|c|}{60} & \multicolumn{2}{|c|}{60} & \multicolumn{2}{|c|}{60} \\
\hline log likelihood & \multicolumn{2}{|c|}{-51.836} & \multicolumn{2}{|c|}{-37.497} & \multicolumn{2}{|c|}{-35.722} & \multicolumn{2}{|c|}{-26.197} \\
\hline
\end{tabular}

Entries are regression coefficients from log-logistic hazard models, where a positive coefficient means that the variable raises the survival probability. Asymptotic standard errors are corrected for correlation across spells for the same coach. 
Table 4: Determinants of Annual Coach Retention (log logistic hazard function, hazard=discharge)

\begin{tabular}{|c|c|c|c|c|c|c|c|c|}
\hline & Coef & $\begin{array}{l}\text { Asy Std } \\
\text { Err }\end{array}$ & Coef & $\begin{array}{l}\text { Asy Std } \\
\text { Err }\end{array}$ & Coef & $\begin{array}{l}\text { Asy Std } \\
\text { Err }\end{array}$ & Coef & $\begin{array}{l}\text { Asy Std } \\
\text { Err }\end{array}$ \\
\hline white coach & 0.2188 & 0.2214 & 0.0486 & 0.1933 & 0.0492 & 0.1887 & -0.1536 & 0.1704 \\
\hline Current Team Winning Percentage & ---- & --- & 3.0796 & 0.9225 & 3.3328 & 0.9418 & 1.7669 & 0.8433 \\
\hline $\begin{array}{l}\text { Current Relative Team Payroll (log ratio of own to } \\
\text { league ave) }\end{array}$ & ---- & ---- & ---- & ---- & -0.3986 & 0.5222 & -0.3645 & 0.3484 \\
\hline age & & & & & & & -0.1133 & 0.1601 \\
\hline age squared & & & & & & & 0.0012 & 0.0017 \\
\hline Years NBA Head Coaching Experience (exp) & ---- & ---- & ---- & ---- & ---- & ---- & 0.0143 & 0.0761 \\
\hline exp squared & ---- & ---- & ---- & ---- & ---- & ---- & -0.0010 & 0.0022 \\
\hline Years College Head Coaching Experience & ---- & ---- & ---- & ---- & ---- & ---- & -0.0053 & 0.0244 \\
\hline Years Pro Non-NBA Head Coaching Experience & ---- & ---- & ---- & ---- & ---- & ---- & -0.0284 & 0.0477 \\
\hline Years as NBA Assistant Coach & ---- & ---- & ---- & ---- & ---- & ---- & -0.0485 & 0.0362 \\
\hline Career NBA Coaching Winning Percentage & ---- & ---- & ---- & ---- & ---- & ---- & 0.5710 & 0.6326 \\
\hline Years in NBA Playoffs as Head Coach & ---- & ---- & ---- & ---- & ---- & ---- & 0.0656 & 0.0990 \\
\hline Years Played in NBA or ABA & ---- & ---- & ---- & ---- & ---- & ---- & -0.0282 & 0.0256 \\
\hline Years as NBA or ABA Allstar Player & \multirow{2}{*}{\multicolumn{2}{|c|}{---- yes }} & ---- & ---- & ---- & ---- & -0.0148 & 0.0522 \\
\hline year dummies? & & & \multicolumn{2}{|c|}{ yes } & \multicolumn{2}{|c|}{ yes } & \multicolumn{2}{|c|}{ yes } \\
\hline Sample size (coach-year observations) & \multicolumn{2}{|c|}{219} & \multicolumn{2}{|c|}{219} & \multicolumn{2}{|c|}{219} & \multicolumn{2}{|c|}{219} \\
\hline Number of Coaches & \multicolumn{2}{|c|}{68} & \multicolumn{2}{|c|}{68} & \multicolumn{2}{|c|}{68} & \multicolumn{2}{|c|}{68} \\
\hline Number of Discharges & \multicolumn{2}{|c|}{41} & \multicolumn{2}{|c|}{41} & \multicolumn{2}{|c|}{41} & \multicolumn{2}{|c|}{41} \\
\hline log likelihood & \multicolumn{2}{|c|}{-52.097} & \multicolumn{2}{|c|}{-42.538} & \multicolumn{2}{|c|}{-42.249} & \multicolumn{2}{|c|}{-32.562} \\
\hline
\end{tabular}

Entries are regression coefficients from log-logistic hazard models, where a positive coefficient means that the variable raises the survival probability. Asymptotic standard errors are corrected for correlation across spells for the same coach. 
Table 5: Determinants of Annual Coach Retention (log logistic hazard function, hazard=quit)

\begin{tabular}{|c|c|c|c|c|c|c|c|c|}
\hline & Coef & $\begin{array}{c}\text { Asy Std } \\
\text { Err }\end{array}$ & Coef & $\begin{array}{c}\text { Asy Std } \\
\text { Err }\end{array}$ & Coef & $\begin{array}{c}\text { Asy Std } \\
\text { Err }\end{array}$ & Coef & $\begin{array}{c}\text { Asy Std } \\
\text { Err }\end{array}$ \\
\hline white coach & 0.2436 & 0.3449 & 0.0601 & 0.2517 & 0.1423 & 0.2737 & 0.2665 & 0.1801 \\
\hline Current Team Winning Percentage & ---- & --- & 2.4381 & 0.5114 & 3.2181 & 0.6679 & 0.5918 & 0.4078 \\
\hline $\begin{array}{l}\text { Current Relative Team Payroll (log ratio of own to } \\
\text { leaque ave) }\end{array}$ & ---- & ---- & ---- & ---- & -1.3698 & 0.4673 & -1.0392 & 0.1616 \\
\hline age & & & & & & & 0.2768 & 0.0902 \\
\hline age squared & & & & & & & -0.0031 & 0.0009 \\
\hline Years NBA Head Coaching Experience (exp) & ---- & ---- & ---- & ---- & ---- & ---- & -0.0454 & 0.0453 \\
\hline exp squared & ---- & ---- & --- & ---- & --- & ---- & 0.0022 & 0.0018 \\
\hline Years College Head Coaching Experience & ---- & ---- & --- & ---- & ---- & --- & 0.0065 & 0.0248 \\
\hline Years Pro Non-NBA Head Coaching Experience & ---- & ---- & ---- & ---- & ---- & ---- & 0.0763 & 0.0312 \\
\hline Years as NBA Assistant Coach & ---- & ---- & ---- & ---- & ---- & ---- & 0.0944 & 0.0164 \\
\hline Career NBA Coaching Winning Percentage & ---- & ---- & ---- & ---- & --- & ---- & 1.2074 & 0.3073 \\
\hline Years in NBA Playoffs as Head Coach & ---- & --- & --- & ---- & --- & ---- & 0.1007 & 0.0430 \\
\hline Years Played in NBA or ABA & ---- & ---- & ---- & ---- & ---- & ---- & -0.0012 & 0.0155 \\
\hline Years as NBA or ABA Allstar Player & ---- & ---- & --- & ---- & --- & ---- & -0.0186 & 0.0175 \\
\hline year dummies? & \multicolumn{2}{|c|}{ yes } & \multicolumn{2}{|c|}{ yes } & \multicolumn{2}{|c|}{ yes } & \multicolumn{2}{|c|}{ yes } \\
\hline Sample size (coach-year observations) & \multicolumn{2}{|c|}{219} & \multicolumn{2}{|c|}{219} & \multicolumn{2}{|c|}{219} & \multicolumn{2}{|c|}{219} \\
\hline Number of Coaches & \multicolumn{2}{|c|}{68} & \multicolumn{2}{|c|}{68} & \multicolumn{2}{|c|}{68} & \multicolumn{2}{|c|}{68} \\
\hline Number of Discharges & \multicolumn{2}{|c|}{19} & \multicolumn{2}{|c|}{19} & \multicolumn{2}{|c|}{19} & \multicolumn{2}{|c|}{19} \\
\hline log likelihood & \multicolumn{2}{|c|}{-37.485} & \multicolumn{2}{|c|}{-31.471} & \multicolumn{2}{|c|}{-28.448} & \multicolumn{2}{|c|}{-10.711} \\
\hline
\end{tabular}

Entries are regression coefficients from log-logistic hazard models, where a positive coefficient means that the variable raises the survival probability. Asymptotic standard errors are corrected for correlation across spells for the same coach. 
Table 6: Determinants of Current Team Winning Percentage

A. Ordinary Least Squares (OLS) Estimates

\begin{tabular}{|c|c|c|c|c|c|c|c|c|}
\hline & Coef & Std Err & Coef & Std Err & Coef & Std Err & Coef & Std Err \\
\hline white coach & 0.0788 & 0.0337 & 0.0647 & 0.0341 & 0.0678 & 0.0377 & 0.0328 & 0.0332 \\
\hline Current Relative Team Payroll (log ratio of own to & & & & & & & & \\
\hline league ave) & ---- & --- & 0.2498 & 0.0647 & 0.1846 & 0.0601 & 0.1457 & 0.0572 \\
\hline age & & & & & -0.0277 & 0.0205 & -0.0282 & 0.0189 \\
\hline age squared & & & & & 0.0002 & 0.0002 & 0.0003 & 0.0002 \\
\hline Years NBA Head Coaching Experience (exp) & ---- & ---- & --- & ---- & 0.0209 & 0.0086 & -0.0113 & 0.0144 \\
\hline exp squared & ---- & ---- & ---- & ---- & -0.0006 & 0.0003 & 0.0000 & 0.0004 \\
\hline Years College Head Coaching Experience & ---- & ---- & ---- & ---- & 0.0028 & 0.0044 & 0.0031 & 0.0045 \\
\hline Years Pro Non-NBA Head Coaching Experience & --- & ---- & ---- & ---- & 0.0136 & 0.0075 & 0.0155 & 0.0063 \\
\hline Years as NBA Assistant Coach & ---- & ---- & ---- & ---- & 0.0073 & 0.0055 & 0.0090 & 0.0050 \\
\hline Career NBA Coaching Winning Percentage & ---- & ---- & ---- & ---- & ---- & ---- & 0.2447 & 0.0915 \\
\hline Years in NBA Playoffs as Head Coach & ---- & ---- & ---- & ---- & ---- & ---- & 0.0184 & 0.0086 \\
\hline Years Played in NBA or ABA & ---- & ---- & ---- & ---- & 0.0081 & 0.0048 & 0.0074 & 0.0045 \\
\hline Years as NBA or ABA Allstar Player & ---- & ---- & ---- & ---- & 0.0079 & 0.0038 & 0.0056 & 0.0045 \\
\hline year dummies? & \multicolumn{2}{|c|}{ yes } & \multicolumn{2}{|c|}{ yes } & \multicolumn{2}{|c|}{ yes } & \multicolumn{2}{|c|}{ yes } \\
\hline
\end{tabular}

\section{B. Quantile (.10) Regression Estimates}

\begin{tabular}{|c|c|c|c|c|c|c|c|c|}
\hline & Coef & $\begin{array}{c}\text { Asy Std } \\
\text { Err }\end{array}$ & Coef & $\begin{array}{c}\text { Asy Std } \\
\text { Err }\end{array}$ & Coef & $\begin{array}{c}\text { Asy Std } \\
\text { Err }\end{array}$ & Coef & $\begin{array}{c}\text { Asy Std } \\
\text { Err }\end{array}$ \\
\hline white coach & 0.0324 & 0.0441 & 0.0594 & 0.0372 & 0.0638 & 0.0663 & -0.0563 & 0.0541 \\
\hline \multicolumn{9}{|l|}{ Current Relative Team Payroll (log ratio of own to } \\
\hline league ave) & --- & --- & 0.2555 & 0.0841 & 0.2806 & 0.0871 & 0.0418 & 0.0897 \\
\hline age & & & & & -0.0544 & 0.0521 & -0.1041 & 0.0389 \\
\hline age squared & & & & & 0.0005 & 0.0006 & 0.0010 & 0.0004 \\
\hline Years NBA Head Coaching Experience (exp) & ---- & ---- & ---- & ---- & 0.0195 & 0.0157 & -0.0253 & 0.0206 \\
\hline exp squared & ---- & ---- & ---- & ---- & -0.0006 & 0.0006 & -0.0002 & 0.0006 \\
\hline Years College Head Coaching Experience & ---- & ---- & ---- & ---- & 0.0027 & 0.0097 & 0.0091 & 0.0085 \\
\hline Years Pro Non-NBA Head Coaching Experience & ---- & ---- & ---- & ---- & 0.0180 & 0.0144 & 0.0338 & 0.0120 \\
\hline Years as NBA Assistant Coach & ---- & ---- & ---- & ---- & 0.0050 & 0.0098 & 0.0149 & 0.0082 \\
\hline Career NBA Coaching Winning Percentage & ---- & ---- & ---- & ---- & ---- & ---- & 0.3690 & 0.1278 \\
\hline Years in NBA Playoffs as Head Coach & ---- & ---- & ---- & ---- & ---- & ---- & 0.0368 & 0.0151 \\
\hline Years Played in NBA or ABA & ---- & ---- & ---- & ---- & 0.0046 & 0.0097 & 0.0111 & 0.0065 \\
\hline Years as NBA or ABA Allstar Player & ---- & ---- & ---- & ---- & 0.0138 & 0.0106 & 0.0083 & 0.0084 \\
\hline year dummies? & \multicolumn{2}{|c|}{ yes } & \multicolumn{2}{|c|}{ yes } & \multicolumn{2}{|c|}{ yes } & \multicolumn{2}{|c|}{ yes } \\
\hline
\end{tabular}


Table 6: Determinants of Current Team Winning Percentage (ctd)

\section{Quantile (.90) Regression Estimates}

\begin{tabular}{|c|c|c|c|c|c|c|c|c|}
\hline & Coef & $\begin{array}{c}\text { Asy Std } \\
\text { Err }\end{array}$ & Coef & $\begin{array}{c}\text { Asy Std } \\
\text { Err }\end{array}$ & Coef & $\begin{array}{c}\text { Asy Std } \\
\text { Err }\end{array}$ & Coef & $\begin{array}{c}\text { Asy Std } \\
\text { Err }\end{array}$ \\
\hline white coach & 0.1098 & 0.0180 & 0.0818 & 0.0297 & 0.0696 & 0.0308 & 0.0614 & 0.0410 \\
\hline $\begin{array}{l}\text { Current Relative Team Payroll (log ratio of own to } \\
\text { leaque ave) }\end{array}$ & --- & ---- & & & 01529 & 0.0773 & 0.1697 & 00867 \\
\hline age & --- & --- & 0.7767 & $0.06 / 6$ & $\begin{array}{r}0.1529 \\
-0.0033\end{array}$ & 0.0240 & $\begin{array}{l}0.169 / \\
-0.0105\end{array}$ & $0.086 / 1$ \\
\hline age squared & & & & & 0.0000 & 0.0002 & 0.0001 & 0.0003 \\
\hline Years NBA Head Coaching Experience (exp) & ---- & --- & ---- & ---- & 0.0108 & 0.0085 & -0.0195 & 0.0152 \\
\hline exp squared & ---- & --- & --- & --- & -0.0004 & 0.0003 & 0.0002 & 0.0004 \\
\hline Years College Head Coaching Experience & --- & --- & --- & --- & -0.0037 & 0.0063 & -0.0026 & 0.0065 \\
\hline Years Pro Non-NBA Head Coaching Experience & ---- & ---- & ---- & --- & -0.0029 & 0.0067 & 0.0023 & 0.0067 \\
\hline Years as NBA Assistant Coach & ---- & ---- & ---- & ---- & 0.0044 & 0.0061 & 0.0066 & 0.0075 \\
\hline Career NBA Coaching Winning Percentage & ---- & ---- & ---- & ---- & ---- & ---- & 0.0855 & 0.0908 \\
\hline Years in NBA Playoffs as Head Coach & --- & --- & ---- & ---- & --- & ---- & 0.0199 & 0.0102 \\
\hline Years Played in NBA or ABA & ---- & ---- & ---- & --- & 0.0018 & 0.0040 & 0.0034 & 0.0044 \\
\hline Years as NBA or ABA Allstar Player & ---- & ---- & ---- & ---- & 0.0016 & 0.0041 & 0.0010 & 0.0053 \\
\hline year dummies? & \multicolumn{2}{|c|}{ yes } & \multicolumn{2}{|c|}{ yes } & \multicolumn{2}{|c|}{ yes } & \multicolumn{2}{|c|}{ yes } \\
\hline
\end{tabular}

Note: standard errors for OLS models are corrected for correlation across observations for a given coach. Quantile regression standard errors are computed using a bootstrapping procedure with 100 iterations. Sample size is 219 . 
Table 7: Determinants of Current Team Winning Percentage, Coaches with Three or Fewer Years of Current Tenure

\section{A. Ordinary Least Squares (OLS) Estimates}

\begin{tabular}{|c|c|c|c|c|c|c|c|c|}
\hline & Coef & Std Err & Coef & Std Err & Coef & Std Err & Coef & Std Err \\
\hline white coach & 0.0502 & 0.0341 & 0.0434 & 0.0343 & 0.0602 & 0.0388 & 0.0222 & 0.0344 \\
\hline Current Relative Team Payroll (log ratio of own to & & & & & & & & \\
\hline league ave) & ---- & ---- & 0.2376 & 0.0666 & 0.1762 & 0.0695 & 0.1458 & 0.0675 \\
\hline age & & & & & -0.0378 & 0.0218 & -0.0354 & 0.0185 \\
\hline age squared & & & & & 0.0003 & 0.0002 & 0.0003 & 0.0002 \\
\hline Years NBA Head Coaching Experience (exp) & ---- & ---- & ---- & ---- & 0.0206 & 0.0092 & -0.0194 & 0.0152 \\
\hline exp squared & ---- & ---- & ---- & ---- & -0.0006 & 0.0003 & 0.000004 & 0.0004 \\
\hline Years College Head Coaching Experience & ---- & ---- & ---- & ---- & 0.0038 & 0.0050 & 0.0043 & 0.0048 \\
\hline Years Pro Non-NBA Head Coaching Experience & ---- & ---- & ---- & ---- & 0.0121 & 0.0086 & 0.0115 & 0.0068 \\
\hline Years as NBA Assistant Coach & ---- & ---- & ---- & ---- & 0.0085 & 0.0062 & 0.0112 & 0.0053 \\
\hline Career NBA Coaching Winning Percentage & ---- & ---- & ---- & ---- & ---- & ---- & 0.2124 & 0.0849 \\
\hline Years in NBA Playoffs as Head Coach & ---- & ---- & ---- & ---- & --- & --- & 0.0313 & 0.0106 \\
\hline Years Played in NBA or ABA & ---- & ---- & ---- & ---- & 0.0079 & 0.0055 & 0.0071 & 0.0051 \\
\hline Years as NBA or ABA Allstar Player & ---- & ---- & ---- & ---- & 0.0110 & 0.0042 & 0.0088 & 0.0043 \\
\hline year dummies? & \multicolumn{2}{|c|}{ yes } & \multicolumn{2}{|c|}{ yes } & \multicolumn{2}{|c|}{ yes } & \multicolumn{2}{|c|}{ yes } \\
\hline
\end{tabular}

B. Quantile (.10) Regression Estimates

\begin{tabular}{|c|c|c|c|c|c|c|c|c|}
\hline & Coef & $\begin{array}{c}\text { Asy Std } \\
\text { Err }\end{array}$ & Coef & $\begin{array}{c}\text { Asy Std } \\
\text { Err }\end{array}$ & Coef & $\begin{array}{c}\text { Asy Std } \\
\text { Err }\end{array}$ & Coef & $\begin{array}{c}\text { Asy Std } \\
\text { Err }\end{array}$ \\
\hline white coach & -0.0163 & 0.0447 & 0.0189 & 0.0429 & 0.0371 & 0.0586 & -0.0350 & 0.0531 \\
\hline Current Relative Team Payroll (log ratio of own to & & & & & & & & \\
\hline league ave) & --- & --- & 0.1815 & 0.1202 & 0.2195 & 0.1091 & -0.0043 & 0.1082 \\
\hline age & & & & & -0.0459 & 0.0620 & -0.0420 & 0.0434 \\
\hline age squared & & & & & 0.0003 & 0.0007 & 0.0004 & 0.0005 \\
\hline Years NBA Head Coaching Experience (exp) & ---- & --- & --- & --- & 0.0271 & 0.0160 & -0.0456 & 0.0238 \\
\hline exp squared & ---- & ---- & ---- & ---- & -0.0007 & 0.0006 & 0.0002 & 0.0007 \\
\hline Years College Head Coaching Experience & ---- & ---- & ---- & ---- & 0.0104 & 0.0099 & 0.0057 & 0.0077 \\
\hline Years Pro Non-NBA Head Coaching Experience & ---- & ---- & ---- & ---- & 0.0271 & 0.0175 & 0.0224 & 0.0140 \\
\hline Years as NBA Assistant Coach & ---- & ---- & ---- & ---- & 0.0145 & 0.0098 & 0.0124 & 0.0071 \\
\hline Career NBA Coaching Winning Percentage & --- & --- & --- & ---- & ---- & ---- & 0.2716 & 0.1322 \\
\hline Years in NBA Playoffs as Head Coach & ---- & --- & ---- & --- & --- & --- & 0.0547 & 0.0203 \\
\hline Years Played in NBA or ABA & --- & --- & --- & --- & 0.0100 & 0.0095 & 0.0084 & 0.0071 \\
\hline Years as NBA or ABA Allstar Player & --- & --- & --- & --- & 0.0213 & 0.0098 & 0.0054 & 0.0074 \\
\hline year dummies? & \multicolumn{2}{|c|}{ yes } & \multicolumn{2}{|c|}{ yes } & \multicolumn{2}{|c|}{ yes } & \multicolumn{2}{|c|}{ yes } \\
\hline
\end{tabular}


Table 7: Determinants of Current Team Winning Percentage, Coaches with Three or Fewer Years of Current Tenure (ctd)

\section{Quantile (.90) Regression Estimates}

\begin{tabular}{|c|c|c|c|c|c|c|c|c|}
\hline & Coef & $\begin{array}{c}\text { Asy Std } \\
\text { Err }\end{array}$ & Coef & $\begin{array}{c}\text { Asy Std } \\
\text { Err }\end{array}$ & Coef & $\begin{array}{c}\text { Asy Std } \\
\text { Err }\end{array}$ & Coef & $\begin{array}{c}\text { Asy Std } \\
\text { Err }\end{array}$ \\
\hline white coach & 0.0854 & 0.0287 & 0.0406 & 0.0332 & 0.0304 & 0.0380 & 0.0263 & 0.0407 \\
\hline Current Relative Team Payroll (log ratio of own to & & & & & & & & \\
\hline $\begin{array}{l}\text { league ave) } \\
\text { age }\end{array}$ & ---- & --- & 0.1959 & 0.0981 & $\begin{array}{c}0.2687 \\
-0.0155\end{array}$ & $\begin{array}{l}0.1035 \\
0.0301\end{array}$ & $\begin{array}{l}0.2445 \\
-0.0127\end{array}$ & $\begin{array}{l}0.1054 \\
0.0300\end{array}$ \\
\hline age squared & & & & & 0.0002 & 0.0003 & 0.0001 & 0.0003 \\
\hline Years NBA Head Coaching Experience (exp) & ---- & ---- & ---- & ---- & 0.0096 & 0.0151 & -0.0205 & 0.0147 \\
\hline exp squared & ---- & ---- & ---- & ---- & -0.0004 & 0.0005 & 0.0004 & 0.0004 \\
\hline Years College Head Coaching Experience & ---- & ---- & ---- & ---- & 0.0008 & 0.0075 & 0.0009 & 0.0054 \\
\hline Years Pro Non-NBA Head Coaching Experience & ---- & ---- & ---- & ---- & 0.0015 & 0.0097 & -0.0015 & 0.0079 \\
\hline Years as NBA Assistant Coach & ---- & ---- & ---- & ---- & 0.0118 & 0.0085 & 0.0132 & 0.0074 \\
\hline Career NBA Coaching Winning Percentage & ---- & ---- & ---- & ---- & ---- & ---- & 0.1658 & 0.1006 \\
\hline Years in NBA Playoffs as Head Coach & ---- & --- & ---- & ---- & ---- & ---- & 0.0205 & 0.0112 \\
\hline Years Played in NBA or ABA & ---- & ---- & ---- & ---- & 0.0044 & 0.0053 & 0.0063 & 0.0052 \\
\hline Years as NBA or ABA Allstar Player & ---- & ---- & ---- & ---- & 0.0058 & 0.0060 & 0.0027 & 0.0063 \\
\hline year dummies? & \multicolumn{2}{|c|}{ yes } & \multicolumn{2}{|c|}{ yes } & \multicolumn{2}{|c|}{ yes } & \multicolumn{2}{|c|}{ yes } \\
\hline
\end{tabular}

Note: standard errors for OLS models are corrected for correlation across observations for a given coach. Quantile regression standard errors are computed using a bootstrapping procedure with 100 iterations. Sample size is 173. 
Table 8: Determinants of Log Annual Compensation (OLS regressions)

\begin{tabular}{|c|c|c|c|c|c|c|c|c|}
\hline & Coef & Std Err & Coef & Std Err & Coef & Std Err & Coef & Std Err \\
\hline white coach & 0.3276 & 0.1414 & 0.1686 & 0.1092 & 0.0983 & 0.0922 & -0.0293 & 0.0947 \\
\hline age & ---- & ---- & -0.1120 & 0.0553 & -0.1616 & 0.0530 & -0.1559 & 0.0518 \\
\hline age squared & ---- & ---- & 0.0009 & 0.0005 & 0.0013 & 0.0005 & 0.0013 & 0.0005 \\
\hline Years NBA Head Coaching Experience (exp) & ---- & ---- & 0.1189 & 0.0261 & 0.1716 & 0.0261 & 0.0583 & 0.0379 \\
\hline exp squared & ---- & ---- & -0.0026 & 0.0010 & -0.0047 & 0.0009 & -0.0030 & 0.0011 \\
\hline Years College Head Coaching Experience & ---- & ---- & ---- & ---- & 0.0383 & 0.0148 & 0.0412 & 0.0134 \\
\hline Years Pro Non-NBA Head Coaching Experience & ---- & ---- & ---- & ---- & 0.0251 & 0.0274 & 0.0339 & 0.0224 \\
\hline Years as NBA Assistant Coach & ---- & ---- & ---- & ---- & -0.0153 & 0.0179 & -0.0056 & 0.0159 \\
\hline Career NBA Coaching Winning Percentage & ---- & ---- & ---- & ---- & ---- & ---- & 0.4734 & 0.2538 \\
\hline Years in NBA Playoffs as Head Coach & ---- & ---- & ---- & ---- & ---- & ---- & 0.0899 & 0.0413 \\
\hline Years Played in NBA or ABA & ---- & ---- & ---- & ---- & 0.0044 & 0.0130 & 0.0067 & 0.0121 \\
\hline Years as NBA or ABA Allstar Player & ---- & ---- & ---- & ---- & 0.0733 & 0.0176 & 0.0749 & 0.0201 \\
\hline year dummies? & \multicolumn{2}{|c|}{ yes } & \multicolumn{2}{|c|}{ yes } & \multicolumn{2}{|c|}{ yes } & \multicolumn{2}{|c|}{ yes } \\
\hline Sample size (coach-contract observations) & \multicolumn{2}{|c|}{90} & \multicolumn{2}{|c|}{90} & \multicolumn{2}{|c|}{90} & \multicolumn{2}{|c|}{90} \\
\hline Number of Coaches & \multicolumn{2}{|c|}{60} & \multicolumn{2}{|c|}{60} & \multicolumn{2}{|c|}{60} & \multicolumn{2}{|c|}{60} \\
\hline R squared & \multicolumn{2}{|c|}{0.2254} & \multicolumn{2}{|c|}{0.5381} & \multicolumn{2}{|c|}{0.6714} & \multicolumn{2}{|c|}{0.7260} \\
\hline
\end{tabular}

Note: dependent variable is log of (total contractwide compensation/duration of contract). Standard errors are corrected for correlation across spells for the same coach. 
Table 9: Determinants of Log Total Contractwide Compensation (OLS regressions)

\begin{tabular}{|c|c|c|c|c|c|c|c|c|}
\hline & Coef & Std Err & Coef & Std Err & Coef & Std Err & Coef & Std Err \\
\hline white coach & 0.3004 & 0.1795 & 0.1867 & 0.1517 & 0.0662 & 0.1305 & -0.0304 & 0.1348 \\
\hline age & ---- & ---- & -0.1645 & 0.0825 & -0.2479 & 0.0920 & -0.2438 & 0.0942 \\
\hline age squared & ---- & ---- & 0.0013 & 0.0009 & 0.0019 & 0.0010 & 0.0019 & 0.0010 \\
\hline Years NBA Head Coaching Experience (exp) & ---- & ---- & 0.1094 & 0.0405 & 0.1931 & 0.0362 & 0.1039 & 0.0572 \\
\hline exp squared & ---- & ---- & -0.0018 & 0.0015 & -0.0050 & 0.0013 & -0.0035 & 0.0017 \\
\hline Years College Head Coaching Experience & ---- & ---- & ---- & ---- & 0.0655 & 0.0237 & 0.0680 & 0.0238 \\
\hline Years Pro Non-NBA Head Coaching Experience & ---- & ---- & ---- & ---- & 0.0420 & 0.0269 & 0.0508 & 0.0279 \\
\hline Years as NBA Assistant Coach & ---- & ---- & ---- & ---- & -0.0247 & 0.0282 & -0.0176 & 0.0278 \\
\hline Career NBA Coaching Winning Percentage & ---- & ---- & ---- & ---- & ---- & ---- & 0.4790 & 0.3584 \\
\hline Years in NBA Playoffs as Head Coach & ---- & ---- & ---- & ---- & ---- & ---- & 0.0621 & 0.0565 \\
\hline Years Played in NBA or ABA & ---- & ---- & ---- & ---- & 0.0102 & 0.0178 & 0.0119 & 0.0186 \\
\hline Years as NBA or ABA Allstar Player & ---- & ---- & ---- & ---- & 0.0987 & 0.0240 & 0.1004 & 0.0264 \\
\hline year dummies? & \multicolumn{2}{|c|}{ yes } & \multicolumn{2}{|c|}{ yes } & \multicolumn{2}{|c|}{ yes } & \multicolumn{2}{|c|}{ yes } \\
\hline Sample size (coach-contract observations) & \multicolumn{2}{|c|}{90} & \multicolumn{2}{|c|}{90} & \multicolumn{2}{|c|}{90} & \multicolumn{2}{|c|}{90} \\
\hline Number of Coaches & \multicolumn{2}{|c|}{60} & \multicolumn{2}{|c|}{60} & \multicolumn{2}{|c|}{60} & \multicolumn{2}{|c|}{60} \\
\hline R squared & \multicolumn{2}{|c|}{0.2217} & \multicolumn{2}{|c|}{0.3944} & \multicolumn{2}{|c|}{0.5523} & \multicolumn{2}{|c|}{0.5697} \\
\hline
\end{tabular}

Standard errors are corrected for correlation across spells for the same coach. 
Table 10: Determinants of Contract Duration in Years (OLS regressions)

\begin{tabular}{|c|c|c|c|c|c|c|c|c|}
\hline & Coef & Std Err & Coef & Std Err & Coef & Std Err & Coef & Std Err \\
\hline white coach & 0.0231 & 0.2249 & 0.0974 & 0.2458 & -0.0286 & 0.2271 & 0.0498 & 0.2268 \\
\hline age & ---- & ---- & -0.1107 & 0.1350 & -0.2882 & 0.1779 & -0.2929 & 0.1782 \\
\hline age squared & ---- & ---- & 0.0008 & 0.0014 & 0.0021 & 0.0018 & 0.0022 & 0.0018 \\
\hline Years NBA Head Coaching Experience (exp) & ---- & ---- & 0.0072 & 0.0666 & 0.1326 & 0.0649 & 0.1874 & 0.1120 \\
\hline exp squared & ---- & ---- & 0.0009 & 0.0024 & -0.0034 & 0.0022 & -0.0034 & 0.0028 \\
\hline Years College Head Coaching Experience & ---- & ---- & ---- & ---- & 0.1277 & 0.0435 & 0.1270 & 0.0444 \\
\hline Years Pro Non-NBA Head Coaching Experience & ---- & ---- & ---- & ---- & 0.0430 & 0.0531 & 0.0466 & 0.0547 \\
\hline Years as NBA Assistant Coach & ---- & ---- & ---- & ---- & -0.0032 & 0.0399 & -0.0097 & 0.0404 \\
\hline Career NBA Coaching Winning Percentage & ---- & ---- & ---- & ---- & ---- & ---- & 0.2261 & 0.7037 \\
\hline Years in NBA Playoffs as Head Coach & ---- & ---- & ---- & ---- & ---- & ---- & -0.0807 & 0.1100 \\
\hline Years Played in NBA or ABA & ---- & ---- & ---- & ---- & 0.0420 & 0.0299 & 0.0403 & 0.0293 \\
\hline Years as NBA or ABA Allstar Player & ---- & ---- & ---- & ---- & 0.0834 & 0.0442 & 0.0843 & 0.0448 \\
\hline year dummies? & \multicolumn{2}{|c|}{ yes } & \multicolumn{2}{|c|}{ yes } & \multicolumn{2}{|c|}{ yes } & \multicolumn{2}{|c|}{ yes } \\
\hline Sample size (coach-contract observations) & \multicolumn{2}{|c|}{90} & \multicolumn{2}{|c|}{90} & \multicolumn{2}{|c|}{90} & \multicolumn{2}{|c|}{90} \\
\hline Number of Coaches & \multicolumn{2}{|c|}{60} & \multicolumn{2}{|c|}{60} & \multicolumn{2}{|c|}{60} & \multicolumn{2}{|c|}{60} \\
\hline R squared & \multicolumn{2}{|c|}{0.3016} & \multicolumn{4}{|c|}{0.3236} & \multicolumn{2}{|c|}{0.4274} \\
\hline
\end{tabular}

Asymptotic standard errors are corrected for correlation across spells for the same coach. 